\title{
MULHERES VÍTIMAS DE VIOLÊNCIA ATENDIDAS EM UM CENTRO DE REFERÊNCIA DE ATENDIMENTO À MULHER
}

WOMEN VICTIMS OF VIOLENCE EVALUATED AT A REFERRAL CENTER FOR WOMEN'S CARE

MUJERES VÍCTIMAS DE VIOLENCIA ATENDIDAS EN UN CENTRO DE REFERENCIA DE ATENCIÓN A MUJERES

Patrícia Pereira Tavares de Alcântara ${ }^{1}$

Gezabell Rodrigues ${ }^{2}$

Geanne Maria Costa Torres ${ }^{3}$

Antonio Germane Alves Pinto ${ }^{4}$

Palavras-chave:

Violência contra a Mulher; Violência por Parceiro Íntimo; Violência de Gênero; Agressão; Direitos Humanos.

Keywords: Violence Against Women; Intimate Partner Violence; Gender-Based Violence; Aggression; Human Rights.

Palabras clave: Violencia contra la Mujer; Violencia de Pareja; Violencia de Género; Agresión; Derechos Humanos.

Submetido: 26/04/2019

Aprovado: 29/11/2019

Autor(a) para Correspondência: Patrícia Pereira Tavares de Alcântara

Av. Dario Rabelo, S/N Santo Antônio - Iguatu-CE 63500-000

E-mail: enfermeira.tavares.81@ gmail.com

\section{RESUMO}

Este artigo descreve as denúncias de violencia contra as mulheres atendidas em um Centro de Referência de Atendimento à Mulher (CRAM) em Crato (CE). Trata-se de estudo descritivo, documental, de natureza retrospectiva e abordagem quantitativa, realizado no primeiro semestre de 2017. Os dados relativos a todas as denúncias de mulheres vítimas de violência foram coletados, por meio de um instrumento fechado para essa finalidade, e submetidos a análise estatística descritiva. As 20 denúncias indicaram maioria das vítimas com até 50 anos de idade $(n=17)$, com registros sem identificação na escolaridade $(n=12)$ e raças parda e branca $(n=15)$. As violências física e psicológica prevaleceram $(n=15)$, tendo como principais agentes violadores ex-cônjuges, companheiros e ex-companheiros $(n=12)$, $e$ as vítimas procuram espontaneamente o CRAM e outros serviços, como Conselho Tutelar e equipes da Estratégia Saúde da Família (ESF) ( $n=$ 14). Logo, a violência contra as mulheres representa um grave problema social que requer conscientização, apoio e atenção por parte das diferentes esferas da sociedade.

1. Enfermeira. Mestre em Desenvolvimento Regional Sustentável pela Universidade Federal do Cariri (UFCA). Professora na Universidade Regional do Cariri (URCA). Membro do Grupo de Pesquisa Clínica, Cuidado e Gestão em Saúde (GCPLIN), da URCA. E-mail: enfermeira.tavares.81@gmail.com 0RCID: https://orcid.org/0000-0003$3337-4845$

2. Fisioterapeuta. Especialista em Cardiopneumologia pela Escola de Saúde Pública do Ceará (ESP/CE). E-mail: abellzge@hotmail.com 0RCID: https://orcid.org/0000-0002-8033-1365

3. Enfermeira. Mestre em Saúde da Família, pela Universidade Estadual do Ceará (UECE). Enfermeira da Estratégia Saúde da Família em Salitre (CE). Membro do GCPLIN, da URCA. E-mail: gmctorres@hotmail.com ORCID: https:// orcid.org/0000-0003-1998-1278

4. Enfermeiro. Doutor em Saúde Coletiva pela UECE. Professor na URCA. Líder do GCPLIN, da URCA. E-mail: germanepinto@hotmail.com ORCID: https://orcid.org/0000-0002-4897-1178 


\section{ABSTRACT}

This article describes the complaints of violence against women evaluated at a Referral Center for Women's Care (Centro de Referência de Atendimento à Mulher [CRAM]) in Crato, Ceará, Brazil. This is a descriptive, documentary, retrospective study, with a quantitative approach, conducted in the first half of 2017. Data on all complaints from women victims of violence were collected, through a closed instrument for this purpose, and submitted to descriptive statistical analysis. The 20 complaints indicated most victims up to 50 years of age $(n=17)$, with unidentified records in schooling $(n=12)$, and brown and white races $(n=15)$. Physical and psychological violences prevailed $(n=15)$, having ex-spouses, partners, and ex-partners as the main perpetrators $(n=12)$, and victims spontaneously seek the CRAM and other services, such as Guardianship Council and Family Health Strategy (FHS) teams $(n=14)$. So, violence against women represents a serious social issue that requires awareness, support, and care from the various spheres of society.

\section{RESUMEN}

Este artículo describe las denuncias de violencia contra las mujeres atendidas en un Centro de Referencia de Atención a Mujeres (Centro de Referência de Atendimento à Mulher [CRAM]) en Crato, Ceará, Brasil. Este es un estudio descriptivo, documental y retrospectivo, con un enfoque cuantitativo, realizado en el primer semestre de 2017. Se recopilaron datos sobre todas las denuncias de mujeres víctimas de violencia, a través de un instrumento cerrado para este propósito, y se sometieron a un análisis estadístico descriptivo. Las 20 denuncias indicaron mayoría de las víctimas de hasta 50 años de edad $(n=17)$, con registros no identificados en la escolaridad ( $n=$ 12) y razas marrón y blanca $(n=15)$. Las violencias físicas y psicológicas prevalecieron $(n=15)$, con ex cónyuges, parejas y ex parejas como los principales perpetradores $(n=12)$, y las víctimas buscan espontáneamente el CRAM y otros servicios, como el Consejo de Tutela y equipos de la Estrategia Salud de la Familia $(E S F)(n=14)$. Por lo tanto, la violencia contra las mujeres representa un problema social grave que requiere conciencia, apoyo y atención de las diversas esferas de la sociedad.

\section{INTRODUÇÃO}

A violência, em suas diversas formas, tem grande impacto na morbimortalidade no setor saúde. Contribui com a perda da qualidade de vida dos cidadãos e aumenta os custos com cuidados à saúde, além do absenteísmo na escola e no trabalho, constituindo uma das mais significativas modalidades de desestruturação familiar e pessoal ${ }^{1}$.

Com base em pesquisas sobre o tema, nota-se a maior ênfase à violência de gênero, sendo a violência contra a mulher a mais investigada, por toda a sua representatividade no decorrer dos tempos. Todavia, nas sociedades em que a definição do gênero feminino tradicionalmente se relaciona à esfera familiar e à maternidade, a referência fundamental da construção social do gênero masculino é sua atividade na sociedade e no ambiente de trabalho, concentrando os valores materiais, o que faz dele o provedor e protetor da família².

Assim, a violência contra as mulheres se apresenta como uma das principais violações dos direitos humanos, atingindo-as em seu direito à vida, à saúde e à integridade física. Em todas as suas formas (violência doméstica, psicológica, física, moral, patrimonial ou sexual, tráfico de mulheres e assédio sexual, entre outras), trata-se de um fenômeno que atinge mulheres de diferentes classes sociais, origens, idades, regiões, estados civis, escolaridade, raças e até orientações sexuais ${ }^{3}$. Esse evento, bastante expressivo, provoca cicatrizes internas e profundas que afetam a autoestima das vítimas ao longo de toda a sua vida.

Tal evento é componente dos vínculos interpessoais e sociais em que o uso de força, ameaças, agressões ou intimidações constituem os principais caminhos para subjugar e obter vantagens sobre o outro, não respeitando idade, gênero, etnia, renda ou fronteira ${ }^{4}$. Além disso, seu aumento desordenado nos últimos anos evidencia as desigualdades culturais entre os sexos, em que o poder e a força física masculina se sobrepõem em atribuições que legitimam e intensificam a violência ${ }^{5}$.

0 Brasil apresenta uma taxa de 4,8 homicídios por 100 mil mulheres, ocupando a $5^{\text {a }}$ posição entre 83 países, conforme dados da Organização Mundial da Saúde (OMS). Efetivamente, só El Salvador, Colômbia e Guatemala (3 países latino-americanos) e a Federação Russa apresentam taxas superiores às do Brasil ${ }^{6-7}$. No Ceará, o número de denúncias de violência doméstica chegou a quase $20 \mathrm{mil} \mathrm{casos}^{8} \mathrm{em}$ 2018. Na região que abrange Crato, Juazeiro do Norte 
e Barbalha (conhecida como CRAJUBAR), os valores registrados pela Delegacia de Defesa da Mulher (DDM) - com 1.933 ocorrências - somados aos demais dados coletados pelas notificações de violência contra a mulher totalizam 2.299 denúncias, perfazendo um total de 6,28 notificações de violência por dia em 2016 ${ }^{\circ}$. Além disso, no mesmo período, em Crato, a DDM contabilizou 771 registros de violência contra a mulher, acrescidos de 134 registros coletados pelos serviços de saúde, totalizando 905 notificações.

Por se tratar de uma questão relevante e complexa, justifica-se, então, o interesse em abordar tal temática, tendo em vista os agravos psíquicos e sociais observados nas mulheres em situação de violência, presentes em todas as esferas da sociedade ${ }^{4}$, com implicações no desenvolvimento das pessoas por afetar suas visões de mundo, suas crenças e suas expectativas - isso abala vidas, famílias e sonhos.

Diante dessa demanda, que permanece invisivel e silenciosa, e ao pensar na importância das redes de atenção para conferir maior celeridade na assistência à mulher em situação de violência, este estudo descreve as denúncias de violência contra as mulheres atendidas em um Centro de Referência de Atendimento à Mulher (CRAM) no Município de Crato.

\section{METODOLOGIA}

Trata-se de estudo descritivo, documental, de natureza retrospectiva e abordagem quantitativa, com utilização dos dados de todas as denúncias de mulheres vítimas de violência residentes em Crato que procuraram o CRAM, no primeiro semestre do ano de 2017.

0 município em estudo, localizado na Região Metropolitana do Cariri (RMC), conhecido por muitos como "Oásis do Sertão", encontra-se na Mesorregião Sul Cearense e na Microrregião Cariri, a $560 \mathrm{~km}$ de distância da capital estadual, Fortaleza. É a segunda cidade mais importante do Cariri em termos econômicos e tem uma população de 130.604 habitantes ${ }^{10}$.

Conta com uma Rede de Enfrentamento à Violência contra a Mulher articulada, com variados equipamentos que se propõem a oferecer assistência, dentre os quais se destaca a DDM, o Juizado de Violência Doméstica e Familiar contra a Mulher, o CRAM, o Conselho Municipal dos Direitos da Mulher Cratense (CMDMC), o Observatório de Violência Domiciliar e Familiar, a Secretaria de Trabalhadores

\section{...demanda, que permanece invisivel \\ e silenciosa...}

Rurais, a Federação dos Trabalhadores Rurais e os movimentos sociais de mulheres.

$0 s$ CRAMs compõem a rede de atendimento às mulheres em situação de violência, balizada pela Política Nacional de Enfrentamento à Violência contra as Mulheres, do Governo Federal, dividida nos setores de Saúde, Justiça, Segurança Pública e Assistência Social. São equipamentos públicos específicos para - acolhimento/atendimento psicológico e social, orientação e encaminhamento jurídico para as mulheres em situação de violência, com o objetivo de fortalecer e resgatar sua cidadania ${ }^{11}$.

0 instrumento de coleta de dados consistiu nas denúncias de mulheres atendidas no CRAM, utilizando como critérios de busca as denúncias realizadas por mulheres residentes em Crato, no primeiro semestre de 2017. A coleta de dados ocorreu em agosto do referido ano, subsidiada por um instrumento fechado para essa finalidade, contendo variáveis relacionadas ao perfil social e demográfico da mulher, como faixa etária, escolaridade e raça, além do tipo de violência, agressor e origem do encaminhamento.

A inclusão dos dados se deu em planilha eletrônica por dupla digitação no software Microsoft Excel, versão 2013, resultando em um banco de dados eletrônico. Os dados compilados foram submetidos a análise estatística descritiva, com cálculo das frequências e dos percentuais estatísticos, gerando as tabelas relativas a perfil social e demográfico da mulher e ao tipo de violência, agressor e origem do encaminhamento. Concluída essa etapa, procedeuse à análise dos resultados e sua interpretação, subsidiada pela literatura pertinente.

0 estudo foi aprovado pelo Comitê de Ética em Pesquisa da Universidade Regional do Cariri (CEP/ URCA), sob o Parecer n. 1.889.662/2016, observando as normas da Resolução n. 466/2012 ${ }^{12}$ e da Resolução n. $510 / 2016^{13}$ do Conselho Nacional de Saúde (CNS).

\section{RESULTADOS E DISCUSSÃ 0}

Foram analisadas 20 denúncias de violência 
contra a mulher no CRAM de Crato. Na Tabela 1 se registram o número (N) e a proporção (\%) dos registros de atendimentos realizados no serviço, mapeando a caracterização das vítimas segundo faixa etária, escolaridade e raça.

Tabela 1 - Caracterização do perfil social e demográfico das mulheres atendidas no CRAM de Crato no primeiro semestre de 2017.

\begin{tabular}{|c|c|c|c|}
\hline Variáveis & Categorias & $\mathbf{N}$ & $\%$ \\
\hline \multirow{4}{*}{ Idade } & 18 e 30 anos & 9 & 45,00 \\
\hline & 31 a 50 anos & 8 & 40,00 \\
\hline & $>50$ & 3 & 15,00 \\
\hline & Média \pm DP $(32,85 \pm 10,66)$ & & \\
\hline \multirow{6}{*}{ Escolaridade } & Ensino Fundamental I incompleto & 1 & 5,00 \\
\hline & Ensino Fundamental II completo & 1 & 5,00 \\
\hline & Ensino Médio incompleto & 1 & 5,00 \\
\hline & Ensino Médio completo & 2 & 10,00 \\
\hline & Ensino Superior & 3 & 15,00 \\
\hline & Não informado & 12 & 60,00 \\
\hline \multirow{3}{*}{ Raça } & Branca & 7 & 35,00 \\
\hline & Negra & 5 & 25,00 \\
\hline & Parda & 8 & 40,00 \\
\hline
\end{tabular}

DP = Desvio padrão.

Fonte: Elaborada pelos autores.

Analisando a Tabela 1, observou-se prevalência de agressão na faixa etária entre 18 e 30 anos, com 45\%, seguida de perto pela faixa entre 31 e 50 anos (40\%).

Esses resultados se assemelham aos de um estudo realizado no Estado de Rondônia, no período de 2007 a 2015, no qual a faixa etária mais acometida em todos os anos foi dos 19 aos 39 anos (57,72\%), seguida pelas adolescentes dos 11 aos 18 anos $(17,75 \%)^{14}$. Outro estudo merece destaque ao analisar a ocorrência de violência de acordo com a idade das mulheres, chamando atenção a menor prevalência de violência física entre as mulheres pertencentes ao grupo dos 50 aos 59 anos em comparação às mulheres mais jovens ${ }^{15}$.

No que tange à escolaridade, na maioria das denúncias ( $60 \%)$ não constava essa informação -um percentual considerado elevado no âmbito deste estudo. Entre as mulheres que apresentaram essa informação, predominou o Ensino Superior (15\%), indicando que a violência de gênero não ocorre apenas nas camadas menos esclarecidas da população. Contudo, deve-se ponderar que o grande número de denúncias com registros ignorados nessa variável dificulta uma análise mais fidedigna quanto à escolaridade das mulheres que denunciam sua situação de violência.

Alguns autores consideram que os poucos anos de estudo podem favorecer o quadro de violência, visto que mulheres mais instruídas costumam ter menor flexibilidade e paciência para suportar situações de violência. Além disso, frequentemente são mulheres que não dependem de seus parceiros em termos econômicos - tal dependência acaba silenciando muitas vítimas de violência por medo do agressor ou da impossibilidade de garantir o próprio sustento ${ }^{16}$.

A violência contra as mulheres ocorre em todos os níveis de escolaridade. Contudo, quanto mais anos de estudo as mulheres possuem, presume-se que tenham maior conhecimento sobre seus direitos de cidadania, o que pode conferir mecanismos pessoais para se afastar de relacionamentos violentos ${ }^{17}$. 0 direito à educação é um instrumento imprescindivel para todo ser humano - o conhecimento favorece a compreensão da realidade e, no caso das mulheres, contribui para que as agressões não sejam permitidas aos parceiros, motivando-as nessa batalha contra a violência.

Em relação à raça, evidenciou-se predominância de mulheres pardas (40\%), seguidas pelas brancas (35\%) contradizendo o senso comum de que as brancas sofrem menos agressão do que as demais. No que se refere a essa variável, esses resultados se assemelham aos disponíveis na literatura ${ }^{18}$ quando se destaca o predomínio 
de mulheres brancas entre as agredidas, chegando a atingir $82,5 \%$ dos casos. A cor negra ficou em terceiro lugar, com um percentual bastante significativo, evidenciando que $2 / 3$ dos casos de violência acometem as mulheres negras ou pardas, como indica outro estudo ${ }^{19}$ que relata $75,2 \%$ de ocorrências envolvendo essas etnias. Independentemente $d a i d_{d e}{ }^{14}$, as pardas ou negras são as mais atingidas pela violência, sobretudo devido aos contextos em que se inserem - que em geral incluem condições precárias de moradia.

Pelo perfil social e demográfico, evidenciou-se que a violência abrange todas as camadas e classes sociais, independentemente de idade, escolaridade e raça, dentre outras variáveis, com ênfase naquela perpetrada contra a mulher, demandando um olhar mais atento a essa questão permeada pela invisibilidade, subnotificação e impunidade. Além disso, mostra-se crucial romper com a cultura de dominação da mulher, tão enraizada em nossa sociedade. $0 \mathrm{~s}$ agravos decorrentes disso ${ }^{20}$ necessitam de intervenções voltadas à equidade de direitos, proteção e segurança.

A Tabela 2 caracteriza as denúncias das mulheres atendidas pelo CRAM.

Tabela 2 - Caracterização dos tipos de violência, agente violador e origem da demanda das mulheres atendidas no CRAM de Crato no primeiro semestre de 2017.

\begin{tabular}{|c|c|c|c|}
\hline Variáveis & Categorias & $\mathrm{N}$ & $\%$ \\
\hline \multirow{2}{*}{ Violência física } & Não & 6 & 30,00 \\
\hline & Sim & 14 & 70,00 \\
\hline \multirow{2}{*}{ Violência psicológica } & Não & 9 & 45,00 \\
\hline & Sim & 11 & 55,00 \\
\hline \multirow{2}{*}{ Violência moral } & Não & 15 & 75,00 \\
\hline & Sim & 5 & 25,00 \\
\hline \multirow{2}{*}{ Violência sexual } & Não & 20 & 100,00 \\
\hline & Sim & 0 & 0,00 \\
\hline \multirow{2}{*}{ Exploração sexual } & Não & 19 & 95,00 \\
\hline & Sim & 1 & 5,00 \\
\hline \multirow{2}{*}{ Exploração econômica } & Não & 19 & 95,00 \\
\hline & Sim & 1 & 5,00 \\
\hline \multirow{2}{*}{ Violência patrimonial } & Não & 18 & 90,00 \\
\hline & Sim & 2 & 10,00 \\
\hline \multirow{2}{*}{ Negligência } & Não & 20 & 100,00 \\
\hline & Sim & 0 & 0,00 \\
\hline \multirow{2}{*}{ Cárcere privado } & Não & 20 & 100,00 \\
\hline & Sim & 0 & 0,00 \\
\hline \multirow{2}{*}{ Outros } & Não & 15 & 75,00 \\
\hline & Sim & 5 & 25,00 \\
\hline \multirow{6}{*}{ Agente violador } & Cônjuge & 2 & 10,00 \\
\hline & Ex-cônjuge & 4 & 20,00 \\
\hline & Companheiro & 4 & 20,00 \\
\hline & Ex-companheiro & 4 & 20,00 \\
\hline & Familiar/parente & 3 & 15,00 \\
\hline & Outros & 3 & 15,00 \\
\hline \multirow{4}{*}{ Origem } & Hospital & 5 & 25,00 \\
\hline & Espontânea & 7 & 35,00 \\
\hline & Delegacia da Mulher & 1 & 5,00 \\
\hline & Outros & 7 & 35,00 \\
\hline
\end{tabular}

Fonte: Elaborada pelos autores.

Dentre os tipos de violência, predominou a violência física $(70 \%)$, seguida pela psicológica ( $55 \%)$. 0utros tipos de violência foram especificados e mostram-se incipientes, contudo, não deixam de ter importância, pois 
nada justifica a situação de violência vivenciada pelas mulheres, que necessitam de apoio e de um olhar mais atento a essa triste realidade e sua transformação.

No Brasil, cerca de 1 em cada 5 mulheres afirma ter sofrido violência doméstica ou intrafamiliar por parte de um homem e 38\% relatam violência psicológica ${ }^{21}$. Por ser um fenômeno complexo, com causas culturais, econômicas e sociais, combinado a pouca visibilidade, ilegalidade e impunidade, a violência doméstica contra mulheres é a tradução real do poder e da força física masculina e da história de desigualdades culturais entre homens e mulheres que, por meio dos papéis estereotipados, legitimam ou exacerbam a violência ${ }^{22}$. Essa relação de poder e de posse do homem traz consequências permanentes para a mulher, seus filhos, a família e a sociedade. Aumenta o consumo de recursos e os gastos no setor saúde, além da necessidade de apoio social e jurídico, com consequências em nível psicológico, social, econômico e laboral ${ }^{23}$.

Pelos dados compilados, averiguou-se que a violência, em sua maioria, é praticada por excônjuges, companheiros e ex-companheiros (60\%). Tal situação ocasiona cicatrizes invisíveis a olho nu, mas dilacerantes nos aspectos psicoemocionais.

Estudos apontam que parceiros e ex-parceiros são os principais autores da violência contra a mulher ${ }^{23}$. Comungando dessa ideia, os agravos são majoritariamente praticados por parceiros de contato intimo, como maridos e namorados, os quais se aproveitam dos laços afetivos e da vulnerabilidade da vítima para a prática das violências ${ }^{14}$. Essa situação representa um grande fardo para quem sofre tais violências, que desestabilizam a dinâmica familiar, ocasionando danos mentais e casos de suicídios por conta desse fenômeno recorrente e permeado por relações de poder e conflito permanente em nossa sociedade.

A violência sofrida pelas mulheres, em suas múltiplas formas de expressão, torna sua vida repleta de percalços e sofrimentos negativos em função da relação de subserviência, pautada pela dominação absoluta do agressor que desencadeou a desestruturação da vida pessoal e familiar ${ }^{22}$. Tratase de um problema extremamente preocupante, que deve ser alvo de reflexão aprofundada, tanto por parte das autoridades e dos profissionais de saúde quanto da sociedade ${ }^{2}$. Contudo, essa situação não deve ser aceita nem tolerada como algo inerente ao ser humano - para reduzir a violência contra a

\section{...torna-se \\ substancial fortalecer as articulações intersetor iais e multidisciplinares para o enfrentamento a esse problema...}

mulher, deve-se fazer valer a legislação nacional de modo consistente e afetivo.

Quanto à origem das mulheres que procuram 0 serviço, verificou-se que, em sua grande maioria, trata-se de demanda espontânea e encaminhamento de outros serviços - Centro de Referência Especializado de Assistência Social (CREAS), Centro de Referência de Assistência Social (CRAS), Conselho Tutelar e equipes da Estratégia Saúde da Família (ESF) -, totalizando $70 \%$, seguida do hospital, com $25 \%$. $\mathrm{Na}$ literatura, não se confirma a predominância das mulheres denunciarem espontaneamente sua situação de violência, devido ao medo ${ }^{22}$ e à dependência financeira da mulher em relação ao parceiro. Evidências $^{24}$ apontam que a maioria das mulheres que vivenciaram a violência física registrou seu boletim de ocorrência na delegacia, por encontrar maior facilidade e segurança para discorrer sobre sua situação de violência.

Para o atendimento eficaz à mulher em situação de violência, mostra-se necessário romper as barreiras entre o consenso discursivo e o dissenso nas ações voltadas a esse público, primando por uma relação de reciprocidade e mutualidade, envolvida por escuta atenta, compreensiva e com acolhimento adequado. Além disso, torna-se substancial fortalecer as articulações intersetoriais e multidisciplinares para o enfrentamento a esse problema, bastante expressivo em nossa sociedade.

A assistência à mulher vítima de violência deve articular ações intersetoriais para uma atenção integral, implicando a interdisciplinaridade de vários setores, como o jurídico, a saúde, o familiar, as organizações não governamentais (0NGs), com enfoque humanizado ${ }^{22}$. Sem dúvida, a criação da Lei Maria da Penha (LMP) representou um avanço enorme na legislação de enfrentamento à violência doméstica e familiar no Brasil. Rompendo com a visão meramente punitivista, a LMP incorporou as perspectivas da prevenção, assistência e contenção 
da violência, além de criar medidas protetivas de urgência e juizados especializados para o julgamento dos crimes que envolvem violência doméstica e familiar ${ }^{25}$.

Inferem-se, então, avanços significativos na luta contra a violência à mulher, com a criação da LMP e de políticas públicas para o enfrentamento às situações de violências. Entretanto, é preciso avançar ainda mais para coibir a violência contra a mulher, fortalecendo as medidas protetivas da LPM, as redes de atendimento, as campanhas de prevenção e combate à violação dos direitos humanos e a questão de gênero, a capacitação de profissionais que atuam nessa área, dentre outras, com vistas a proporcionar maior visibilidade, efetividade e resolubilidade em sua execução.

\section{CONCLUSÃO}

Os dados compilados e os resultados deste estudo possibilitaram a análise dos registros das mulheres em situação de violência, demonstrando que o perfil das vítimas, majoritariamente, consiste em mulheres até 50 anos, pardas e brancas. No tocante à escolaridade, prevaleceram os registros ignorados, inviabilizando uma investigação mais acurada da relação entre violência e estudo. Ao mesmo tempo, evidenciou-se prevalência das violências física e psicológica sofridas pelas mulheres, tendo como agente violador parceiros e ex-parceiros, e elas procuraram espontaneamente o CRAM como rede de apoio para denunciar as violências sofridas.

Ao mesmo tempo, percebeu-se que a violência contra a mulher constitui um grave problema social, de relações de poder e conflito permanente, requerendo maior conscientização, apoio e atenção das diferentes esferas da sociedade. É imperioso que as vítimas denunciem os agressores e preencham todos os campos disponiveis nas fichas de atendimento, para gerar dados mais consistentes e proporcionar maior visibilidade a esse fenômeno tão alarmante.

Diante da complexidade que permeia a violência contra as mulheres, faz-se necessário derrubar os muros que protegem o ciclo da violência, buscando fortalecer os fluxos de atendimento e as medidas protetivas, de combate, prevenção e tratamento, subsidiados pela intersetorialidade e por equipes multiprofissionais, com o intuito de proporcionar a integralidade do cuidado às mulheres em situação de violência. Muito já se avançou na legislação para o enfrentamento à violência contra a mulher, no

\section{...faz-se necessário derrubar os muros que \\ protegem o ciclo da violência...}

entanto, ainda há um longo caminho a ser percorrido para a garantia plena dos direitos às mulheres, pois esse grave problema social requer conscientização, apoio e atenção das diferentes esferas da sociedade.

Uma das limitações deste estudo consiste nas falhas identificadas no preenchimento das fichas de atendimento, ignorando informações relevantes, como renda, situação conjugal, profissão, tempo de convivência com o cônjuge, faixa etária dos filhos, local da ocorrência, horário da violência sofrida, sentimentos em relação ao agressor. Esses fatores influenciam a generalização dos dados, o que demanda cautela, levando-se em conta a significativa proporção de mulheres em situação de violência que não procuraram a DDM para denunciar seus agressores.

Acredita-se, ainda, que este estudo pode disseminar subsídios científicos acerca desse fenômeno multifacetado, contribuindo para a aquisição de novos conhecimentos por parte das equipes multiprofissionais que atuam nas diversas áreas em que o tema abordado se destaca. Partindo dessa premissa, espera-se contribuir com o desenvolvimento de reflexões mais aprofundadas acerca dessa questão complexa, permeada por relações de poder e conflito permanente, em busca de transformações assentadas em bases sólidas para uma atuação e intervenção na violência contra a mulher que proporcione melhor qualidade de vida a essa população. Sugere-se, então, que novas pesquisas sejam realizadas para subsidiar a efetiva proteção às mulheres vítimas de violência.

\section{CONTRIBUIÇÃO DOS AUTORES}

Patricia Pereira Tavares de Alcântara e Gezabell Rodrigues contribuíram com a realização da pesquisa, o delineamento do estudo e a redação do manuscrito. Geanne Maria Costa Torres contribuiu com o delineamento do estudo e a redação do manuscrito. Antonio Germane Alves Pinto contribuiu com o delineamento do estudo e a revisão crítica do manuscrito. 


\section{REFERÊNCIAS}

1. Brasil. Viva: instrutivo de notificação de violência doméstica, sexual e outras violências. Brasília (DF): Ministério da Saúde; 2011.

2. Gomes SC, Pereira AP, Holanda CAS, Costa Júnior AF, Oliveira JD, Quirino GS. Análise de dados sociodemográficos de notificações de violência psicológica e moral. Sanare (Sobral, Online) [serial on the internet]. 2015 [cited 2019 Jan 16];14(2):518. Available from: https://sanare.emnuvens.com.br/ sanare/article/view/825

3. Brasil. Política Nacional de Enfrentamento à Violência contra as Mulheres. Brasília (DF): Ministério da Saúde; 2011.

4. Pereira RCBR, Loreto MDS, Teixeira KMD, Sousa JMM. 0 fenômeno da violência patrimonial contra a mulher: percepções das vítimas. 0ikos: Revista Brasileira de Economia Doméstica [serial on the internet]. 2013 [cited 2019 Jan 20];24(1):20635. Available from: http://www.locus.ufv.br/ bitstream/handle/123456789/13801/89-674-2-PB. pdf? sequence $=1$ \&is Allowed $=y$

5. Organización Mundial de la Salud. Estimaciones mundiales y regionales de la violencia contra la mujer: prevalencia y efectos de la violencia conyugal y de la violencia sexual no conyugal en la salud [document on the internet]. 2013 [cited 2019 Jan 20]. Available from: https://apps.who. int/iris/bitstream/handle/10665/85243/WHO RHR HRP 13.06 spa.pdf;jsessionid = CAE3835418D7CE3F0 AD8922357B82062? sequence $=1$

6. Waiselfisz JJ. Mapa da Violência 2015: homicídio de mulheres no Brasil [homepage on the internet]. 2015 [cited 2019 Mar 20]. Available from: http:// www.mapadaviolencia.org.br/mapa2015 mulheres. php

7. Organização Pan-Americana da Saúde. Violência contra as mulheres na América Latina e no Caribe: uma análise comparativa dos dados sobre a população de 12 países. Washington (DC): OPAS; 2013.

8. Paulino N, Pinusa S. Ceará foi o segundo estado onde mais se matou mulheres em 2018 [homepage on the internet]. [cited 2019 April 20]. Available from: https://g1.globo.com/ce/noticia/2019/03/08/ ceara-foi-o-segundo-estado-onde-mais-se-matoumulheres-em-2018.ghtml

9. Araújo MLG, Albuquerque GA, Alencar $0 M$. Monitoramento dos casos de violência contra a mulher na Região do Cariri, em 2016, realizado pelo Observatório da Violência e dos Direitos Humanos da Região do Cariri - Universidade Regional do Cariri (URCA) [document on the internet]. 2018 [cited 2019 Mar 20]. Available from: http://www.urca.br/ novo/portal/index.php/documentos/category/12caderno-tematico-violencia-contra-a-mulherda-regiao-do-cariri?download $=27 \% 3$ Acadernotematico-violencia-contra-a-mulher-da-regiao-do$\underline{\text { cariri }}$

10. Instituto de Pesquisa e Estratégia Econômica do Ceará. Perfil municipal 2017 [homepage on the internet]. 2017 [cited 2019 Apr 20]. Available from: https://www.ipece.ce.gov.br/perfil-municipal-2017/

11. Brasil. Presidência da República. Secretaria Nacional de Enfrentamento à Violência contra as Mulheres. Política Nacional de Enfrentamento à Violência Contra as Mulheres [Internet]. Brasília; 2011 [cited 2019 Apr 14]. Available from: https://www12.senado.leg.br/institucional/omv/ entenda-a-violencia/pdfs/politica-nacional-deenfrentamento-a-violencia-contra-as-mulheres

12. Conselho Nacional de Saúde. Resolução n. 466, de 12 de dezembro de 2012 [document on the internet]. 2012 [cited 2019 Apr 14]. Available from: http:// bvsms.saude.gov.br/bvs/saudelegis/cns/2013/ res0466 $12 \quad 12 \quad 2012 . h t m l$

13. Conselho Nacional de Saúde. Resolução n. 510, de 7 de abril de 2016 [document on the internet]. 2016 [cited 2019 Apr 14]. Available from: http:// conselho.saude.gov.br/resolucoes/2016/Res0510.pdf

14. Oliveira CAB, Alencar LN, Cardena RR, Moreira KFA, Pereira PPS, Fernandes DER. Perfil da vítima e características da violência contra a mulher no Estado de Rondônia - Brasil. Rev Cuid (Bucaramanga, 2010) [serial on the internet]. 2019 [cited 2019 Apr 20];10(1):e573. Available from: https:// revistacuidarte.udes.edu.co/index.php/cuidarte/ article/view/573/1052

15. Leite FMC, Amorim MHC, Wehrmeister FC, Gigante DP. Violência contra a mulher em Vitória, Espírito Santo, Brasil. Rev Saúde Pública [serial on the internet]. 2017 [cited 2019 Apr 19];(51):33. Available from: http://www.scielo.br/scielo.php?script=sci arttext\&pid $=$ S0034-89102017000100223\&lng $=$ en

16. Moura TC, Paixão GPN, Silva Filho CC, Carvalho MRS, Oliveira KA, Salgado MA, et al. Violência contra mulher: conhecendo aspectos do perfil das notificações do Município de Senhor do BonfimBahia. Ciência \& Desenvolvimento: Revista Eletrônica da FAINOR [serial on the internet]. 2014 [cited 2019 Apr 19];7(1):156-70. Available from: http://srv02. fainor.com.br/revista/index.php/memorias/article/ view $/ 265$

17. Albuquerque Netto L, Moura MAV, Silva GF, Penna LHG, Pereira ALF. Mulheres em situação de violência pelo parceiro íntimo: tomada de decisão por apoio institucional especializado. Rev Gaúch Enferm [serial on the internet]. 2015 [cited 2019 Apr 19];36(Spec):135-42. Available 
from: http://www.scielo.br/scielo.php?pid=S1983$14472015000500135 \&$ script $=s c i$ abstract\&tlng $=p t$

18. Acosta DF, Gomes VL0, Barlem ELD. Perfil das ocorrências policiais de violência contra a mulher. Acta Paul Enferm [serial on the internet]. 2013 [cited 2019 Jan 25];26(6):547-53. Available from: http://www.scielo.br/scielo.php?script=sci abstract \&pid $=$ S0103-21002013000600007\&lng =en\& $\underline{\mathrm{nrm}}=\mathrm{i}$ so \& $\mathrm{t} \operatorname{lng}=\mathrm{pt}$

19. Melo ACM, Garcia LP. Atendimentos de jovens vítimas de agressões em serviços públicos de urgência e emergência, 2011: diferenças entre sexos. Ciênc Saúde Colet [serial on the internet]. 2017 [cited 2019 Jan 25];22(4):1333-41. Available from: http://www.scielo.br/scielo.php?pid=S1413$\underline{81232017002401333 \& \mathrm{script}=\mathrm{sci} \text { abstract\&tlng }=\mathrm{pt}}$

20. Silva EB, Padoin SMM, Vianna LAC. Mulher em situação de violência: limites da assistência. Ciênc Saúde Colet [serial on the internet]. 2015 [cited 2019 Apr 25];20(1):249-58. Available from: http://www.scielo.br/pdf/csc/v20n1/pt 1413-8123csc-20-01-00249.pdf

21. Senado Federal. Violência doméstica e familiar contra a mulher [document on the internet]. 2013 [cited 2019 Apr 14]. Available from: https://www12. senado.leg.br/institucional/datasenado/arquivos/ aumenta-numero-de-mulheres-que-declaram-tersofrido-violencia

22. Oliveira PP, Viegas SMF, Santos WJ, Silveira EAA, Elias SC. Mulheres vitimas de violência doméstica: uma abordagem fenomenológica. Texto \& Contexto Enferm [serial on the internet]. 2015 [cited 2019 Jan 20];24(1):196-203. Available from: http:// www.scielo.br/pdf/tce/v24n1/pt 0104-0707tce-24-01-00196.pdf

23. Calvinho ML, Ramos N. Violência conjugal contra a mulher, saúde e gênero contributos para melhorar as práticas profissionais e as políticas de prevenção da violência. Revista Ambivalências [serial on the internet]. 2014 [cited 2018 Jan 20];2(3):42-69. Available from: https://seer.ufs.br/index.php/ Ambivalencias/article/view/3127

24. Moura MAV, Albuquerque Netto L, Leite FMC, Lima FRS, Teixeira SVB. Mulheres que denunciam violência de gênero em uma Unidade de Polícia Pacificadora. Rev Eletrônica Enferm [serial on the internet]. 2018 [cited 2019 Apr 20];15(3):628-37. Available from: https://www.fen.ufg.br/revista/v15/n3/pdf/ v15n3a04.pdf

25. Campos CH. The Joint Parliamentary Committee of Enquiry and the Implementation of the Maria da Penha Law. Revista Estudos Feministas [serial on the internet]. 2015 [cited 2019 Jan 20];23(2):51931. Available from: http://www.scielo.br/ scielo.php?script $=$ sci arttext\&pid=S0104$\underline{026 \times 2015000200519}$

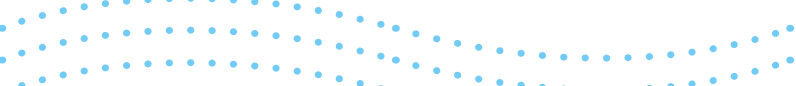

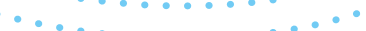

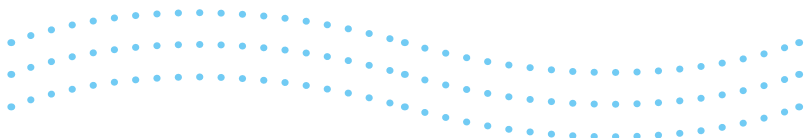

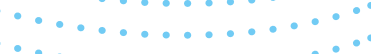
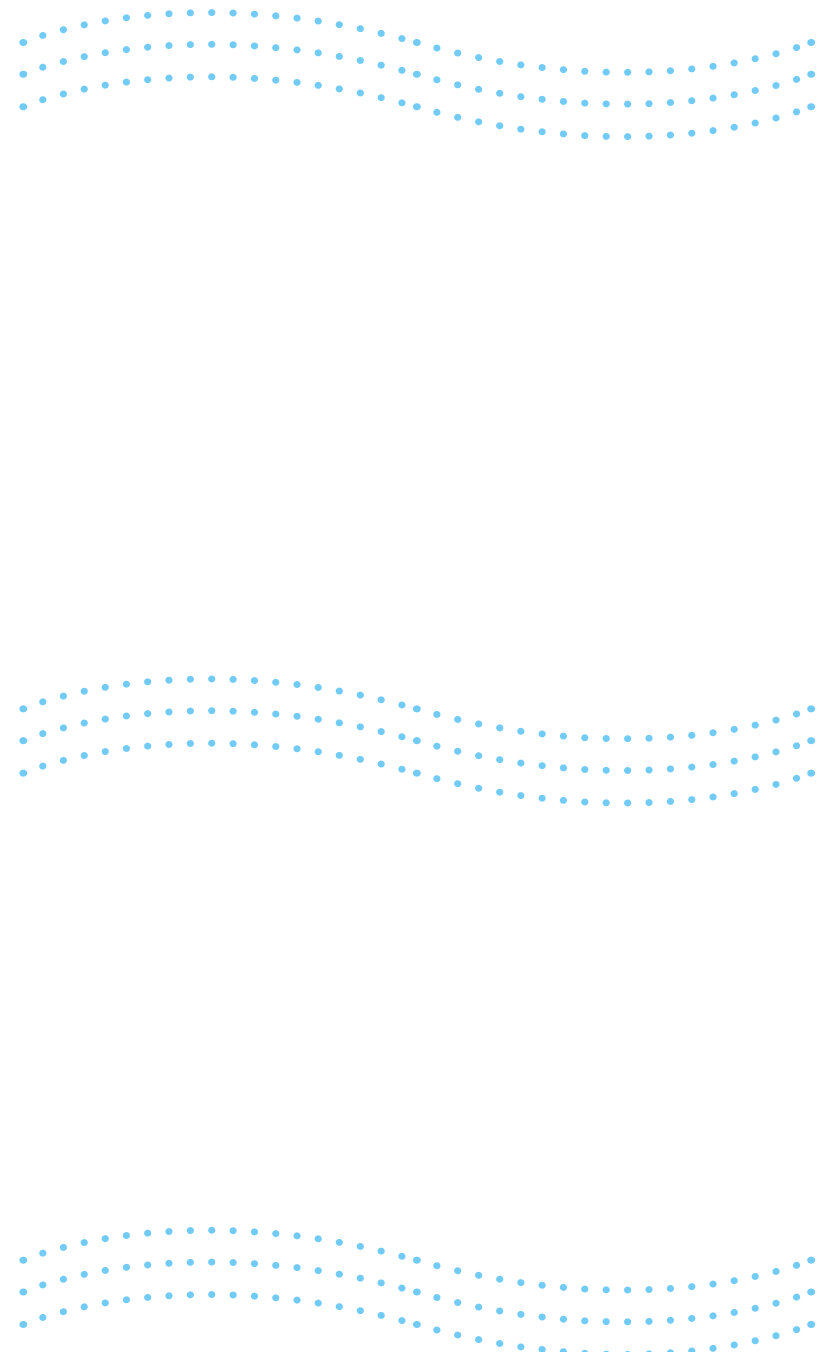